\title{
Study on Fine Particle Flow Characteristics with Different Air Supply Parameters
}

\author{
Min Dong ${ }^{1}$, Cheng-zhi Wang ${ }^{1}$, Lu Zhang $^{1}$ \\ ${ }^{1}$ Shandong HuaYu University of Technology, Shandong Dezhou
}

\begin{abstract}
With the help of FLUENT software, the flow characteristics of fine particles in the upper air supply room with different air supply parameters were studied. The particle trajectory model was established to calculate the concentration distribution characteristics of fine particles in the upper air supply room, and the optimal air supply parameters in the working area of the personnel were researched to reduce the impact of the particles on the human health. By calculating the distribution of air flow field and particle concentration under four different air supply parameters, the optimal operating conditions were obtained by comparative analysis, that is, the air supply temperature was $20^{\circ} \mathrm{C}$ and the air supply speed was $3 \mathrm{~m} / \mathrm{s}$, which provided a theoretical basis for the setting of the air supply parameters of the upper air supply room in the future.
\end{abstract}

\section{Foreword}

With the emergence of the new coronavirus pneumonia epidemic in 2020, everyone will be isolated at home as far as possible. Therefore, the quality of indoor air will directly affect our body construction. Under the condition of effective control of indoor air flow organization, improve indoor Air quality, reducing the impact of indoor pollutants on people ${ }^{[1]}$, and improving people's comfort become particularly important. Computing and analyzing the air flow field and particle concentration distribution under four different air supply parameters and comparing and analyzing to obtain the optimal working conditions, which provides a certain theoretical basis for the setting of air supply parameters for the upper air supply room in future projects.

\section{Calculation model}

\subsection{Physical models and computational grids}

The geometric model created in this simulation is $4000 \mathrm{~mm} \times 3900 \mathrm{~mm} \times 2500 \mathrm{~mm}$, by creating a threedimensional physical model.A computer and a human are established. The geometric model and physical model are shown in Fig1

\subsection{Mathematical Model}

The interior of the upper air supply room is unsteady turbulent flow. so the turbulence model in the calculation is selected as the $\mathrm{k}$-e two equation turbulence model. This simulation uses the Euler-Lagrangian model (k-e model) to perform numerical simulation on the discrete phases.
Tracking particle trajectories simulates discrete phase motion.

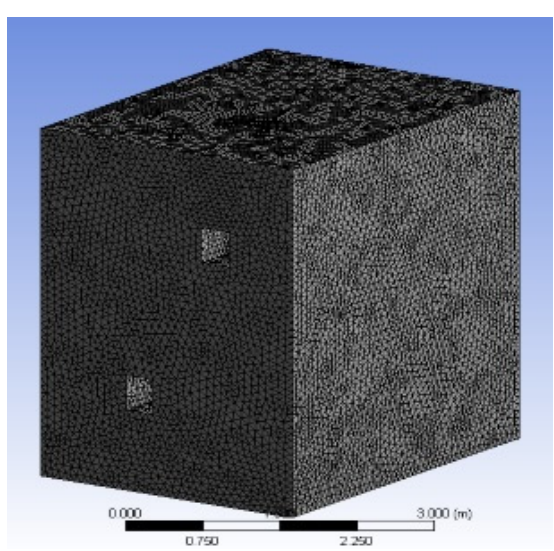

Fig 1 Physical model

The governing equation is as follows:

Energy conservation equation ${ }^{[2]}$ :

$$
\frac{\partial}{\partial t}(\rho e)+\nabla(\rho v \cdot e)=\nabla(k \cdot \nabla T)+q+\varepsilon
$$

Momentum conservation equation:

$$
\begin{array}{r}
\frac{\partial(\rho u)}{\partial \tau}+\frac{\partial(\rho \mu \mu)}{\partial x}+\frac{\partial(\rho \theta \mu)}{\partial y}+\frac{\partial(\rho \mu \omega)}{\partial z}= \\
-\frac{\partial \rho}{\partial x}+\frac{\partial}{\partial x}\left(\lambda d i v u+2 \mu \frac{\partial u}{\partial x}\right)+\frac{\partial}{\partial y}\left[\mu\left(\frac{\partial v}{\partial x}+\frac{\partial u}{\partial y}\right)\right]+\frac{\partial}{\partial z}\left[\mu\left(\frac{\partial v}{\partial z}+\frac{\partial u}{\partial x}\right)\right]+\rho F_{x}
\end{array}
$$

Mass conservation equation:

$$
\frac{\partial \rho}{\partial t}+\nabla(\rho v)=0
$$

Where: $k$-Fluid turbulent flow energy, $\mathrm{J} ; P$-Hourly 
pressure, $\mathrm{Pa} ; p_{r}$-Prandtl number; $\tau$-Time constant, s; $u_{i}$-Speed component, $i=1,2,3$ represents the $\mathrm{x}, \mathrm{y}$, and $\mathrm{z}$ directions respectively; $\varepsilon$-Turbulent energy dissipation, $\% ; \quad \rho$-Fluid density, $\mathrm{kg} / \mathrm{m} 3 ; \quad \beta$-Fluid volume expansion coefficient.

\subsection{Boundary Conditions}

The boundary conditions of the air inlet are set to velocity inlet-inlet. The boundary conditions of the return air outlet are set to the free flow boundary condition outflow. The initial parameters was set : the heat flux of each person is $50 \mathrm{w} / \mathrm{m}^{2}$, and the heat flux of each computer is $100 \mathrm{w} / \mathrm{m}^{2}$. The indoor air density is $1.225 \mathrm{~kg} / \mathrm{m}^{3}$. Air viscosity coefficient is $1.789 e-5 \mathrm{~kg} / \mathrm{m} \cdot \mathrm{s}$.

The time of the particle source releases is 300s. The time step size is set to $0.05 \mathrm{~s}$. The number of time steps is set to 10000 , and the number of time step iterations is set to 10 . The Reporting Interval is set to 1 , and the Profile Update Iterval is set to the default value of 1 .

\begin{tabular}{|c|c|c|}
\hline $\begin{array}{c}\text { Working } \\
\text { condition }\end{array}$ & $\begin{array}{c}\text { Supply air } \\
\text { temperature }(\mathrm{k})\end{array}$ & $\begin{array}{c}\text { Air supply } \\
\text { speed }(\mathrm{m} / \mathrm{s})\end{array}$ \\
\hline A1 & 293 & 2.6 \\
\hline A2 & 297 & 2.6 \\
\hline A3 & 293 & 3 \\
\hline A4 & 297 & 3 \\
\hline
\end{tabular}

\subsection{Temperature field simulation}

A1 working condition: when the air supply temperature is $293 \mathrm{~K}$ and the air supply speed is $2.6 \mathrm{~m} / \mathrm{s}$. The temperature fields obtained are shown in Fig. 4.1 and Fig. 4.2 respectively.

When the supply air velocity of $2.6 \mathrm{~m} / \mathrm{s}$, supply air temperature is $293 \mathrm{k}, \mathrm{y}=1.5 \mathrm{~m}$ height in temperature field distribution range is $303 \mathrm{k}, 308 \mathrm{k}$, because computers and personnel of the heat flux is larger, so the highest temperature appears around the computer, about $308 \mathrm{k}$, findings and the personnel area is about $307 \mathrm{k}$, the wall around the lowest temperature, the temperature of the temperature field distribution in cascade centered on computers and personnel to decline gradually. At the height of $\mathrm{y}=1 \mathrm{~m}$, the temperature field distribution ranges from $303 \mathrm{~K}$ to $317 \mathrm{~K}$. The highest temperature appears around the computer (about $317 \mathrm{~K}$ ), followed by the area where the personnel are located (about 308K). The temperature around the wall is the lowest.

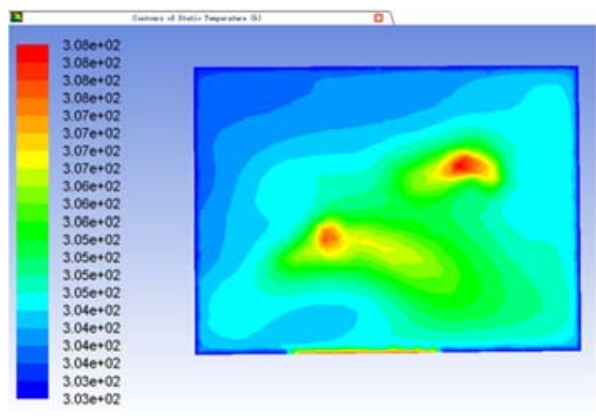

Fig 2 Temperature distribution at the height of $y=1.5 \mathrm{~m}$

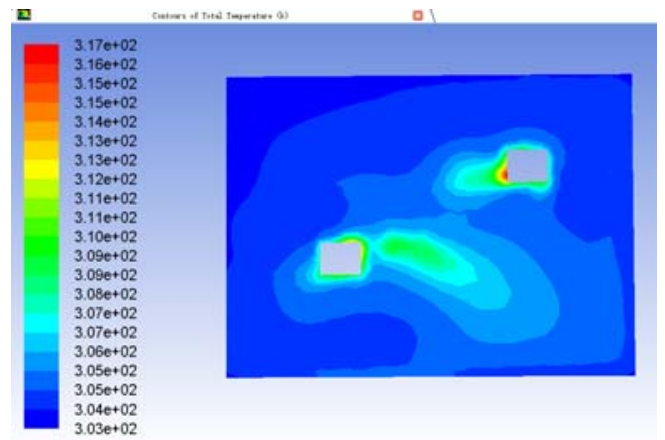

Fig 3 Temperature distribution at the height of $y=1 \mathrm{~m}$

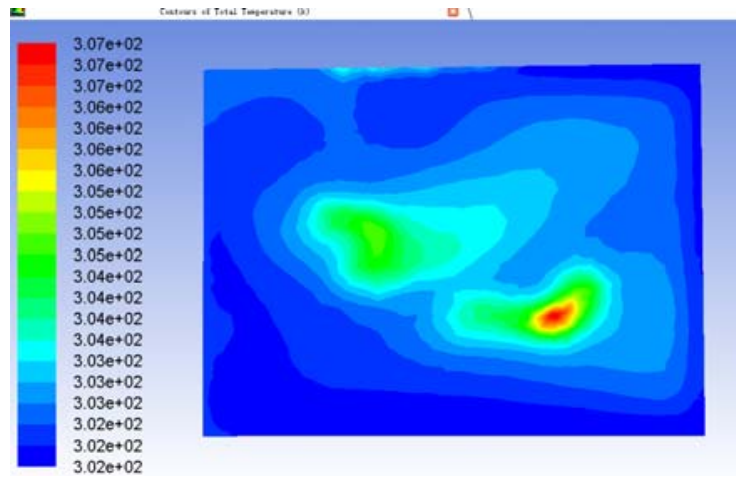

Fig 4 Temperature distribution at the height of $y=1.5 \mathrm{~m}$

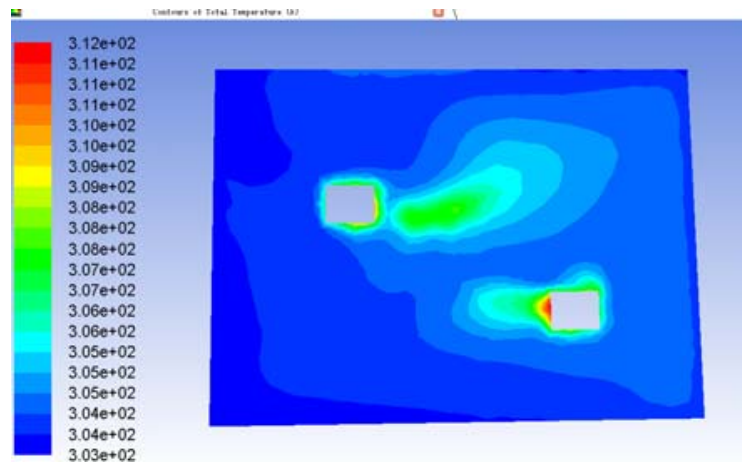

Fig 5 Temperature distribution at the height of $y=1 \mathrm{~m}$

When the supply air velocity of $2.6 \mathrm{~m} / \mathrm{s}$, supply air temperature is $297 \mathrm{k}, \mathrm{y}=1.5 \mathrm{~m}$ height in temperature field distribution range is $302 \mathrm{k}, 307 \mathrm{k}$, because computers and personnel of the heat flux is larger, so the highest temperature appears around the computer, about $307 \mathrm{k}$, findings and the personnel area is about $306 \mathrm{k}$, the wall around the lowest temperature, the temperature of the 
temperature field distribution in cascade centered on computers and personnel to decline gradually. At the height of $\mathrm{y}=1 \mathrm{~m}$, the temperature field distribution ranges from $303 \mathrm{~K}$ to $312 \mathrm{~K}$. The highest temperature appears around the computer (about $312 \mathrm{~K}$ ), followed by the area where the personnel are located (about 308K). The temperature around the wall is the lowest.

\subsection{Velocity field simulation}

In the office area, the sitting time of the personnel is relatively long. The sitting height is about $1 \mathrm{~m}$. Therefore, this paper mainly calculates the distribution of the speed field at the height of $y=1 \mathrm{~m}$ as shown in Fig 6, Fig 7, Fig 8 and Fig 9.

At the height of $y=1 \mathrm{~m}$, the flow velocity is $0.081 \mathrm{~m} / \mathrm{s} \sim 0.128 \mathrm{~m} / \mathrm{s}$ and $0.985 \mathrm{~m} / \mathrm{s} \sim 0.144 \mathrm{~m} / \mathrm{s}$ under the conditions of A1 and A2 . The human body feels uncom fortable and there will be a feeling of stagnant air when the minimum velocity is lower than $0.127 \mathrm{~m} / \mathrm{s}$. Under A3 condition, the flow velocity is $0.166 / \mathrm{s}-0.23 \mathrm{~m} / \mathrm{s}$. The

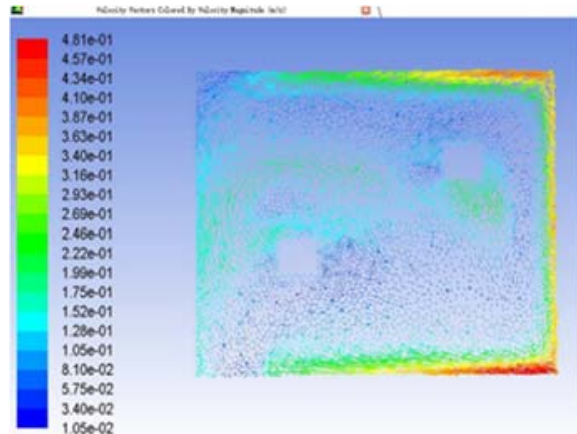

Fig 6 A1 working condition

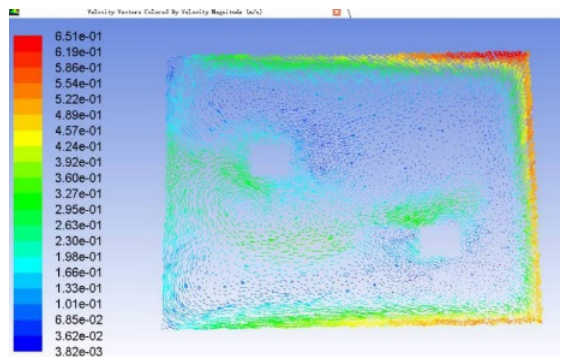

Fig 8 A3 working condition interval value meets the range of human comfort $(0.127-0.25 \mathrm{~m} / \mathrm{s})$. The flow velocity is $0.137 / \mathrm{s}$ $0.202 \mathrm{~m} / \mathrm{s}$ under the A4 condition, which also meets the human body's requirements. Therefore, the A3 and A4 conditio-ns meet the human body's comfort for wind speed..

\subsection{Particle concentration simulation}

At the height of $y=1 \mathrm{~m}$, the particle concentration distribution under the four working conditions is shown in Fig 10, Fig 11, Fig 12 and Fig 13. The average particle concentration around the person is highest at $\mathrm{A} 1$, which is $2.82 \mathrm{e}-07 \mathrm{~kg} / \mathrm{m}^{3}$. A2 conditions is $2.62 \mathrm{e}-07 \mathrm{~kg} / \mathrm{m}^{3}$. average particle concentration around personnel under

A3 conditions is $2.08 \mathrm{e}-07 \mathrm{~kg} / \mathrm{m}^{3}$. A4 conditions is the lowest of the four working conditions, which is $2.26 \mathrm{e}-$ $07 \mathrm{~kg} / \mathrm{m}^{3}$. So for human health considerations, the A3 working condition was finally determined. Which supply air temperature is $20^{\circ} \mathrm{C}$, and the supply air speed is $3 \mathrm{~m} / \mathrm{s}$ are the optimal working condition.

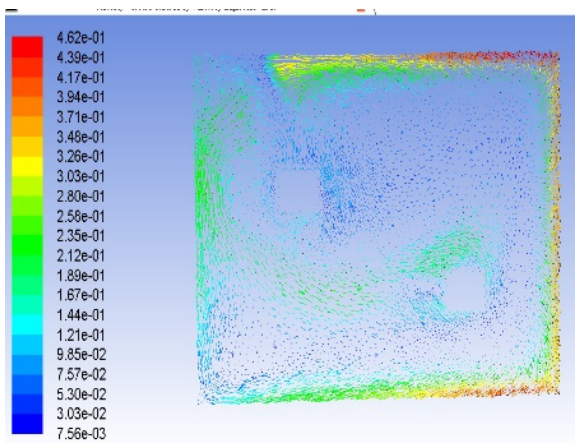

Fig 7 A2 working condition

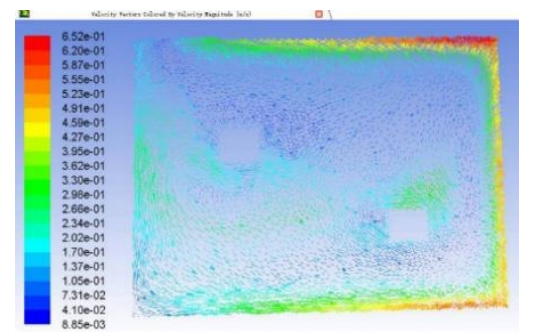

Fig 9 A4 working condition

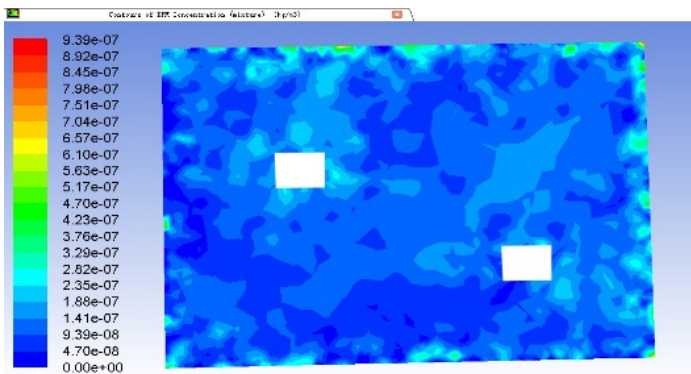

Fig 10 A1 working condition

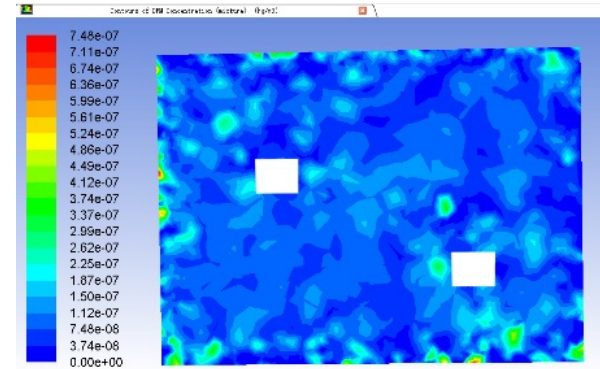

Fig11 A2 working condition 


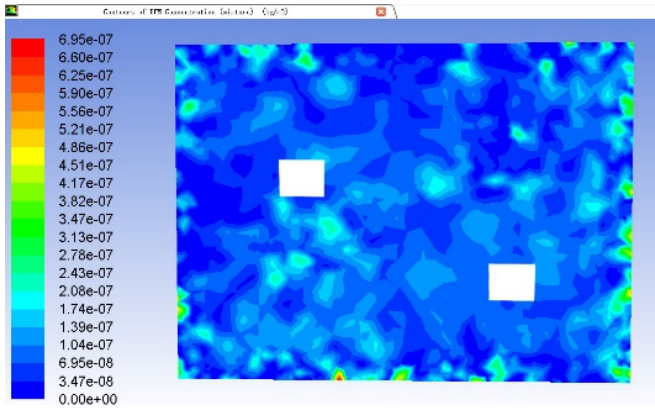

Fig 12 A3 working condition

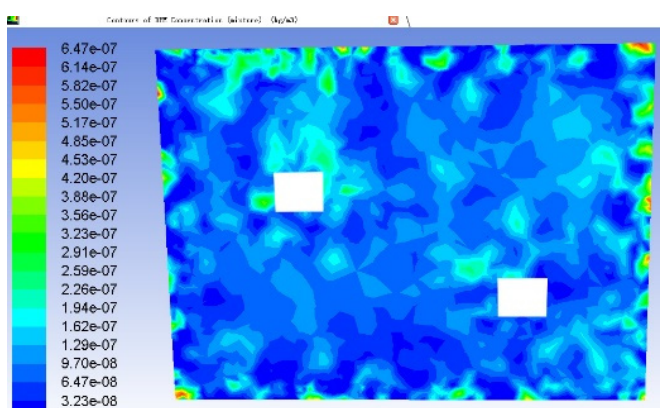

Fig 13 A4 working condition

Particle concentration distribution under four conditions at $\mathrm{y}=1 \mathrm{~m}$

Combining the velocity field and the particle concentration distribution, A3 operating condition (supply air temperature of $20^{\circ} \mathrm{C}$ and air velocity of $3 \mathrm{~m} / \mathrm{s}$ ) was the optimal operating condition.

\section{Conclusion:}

This paper numerically simulates different air supply parameters of the upper air supply room, analyzes and compares the indoor flow field of different air supply parameters and the cloud diagram of particle concentration distribution, and finds the optimal working conditions. After numerical analysis and comparison, the following conclusions are obtained:

1. Speed simulation. At the height of $y=1 \mathrm{~m}$, the speed around people under the A1 and A2 working conditions is low. A3 and A4 working conditions meet the range of human comfort;

2. Particle concentration simulation. At the height of $\mathrm{y}=1 \mathrm{~m}$, the particle concentration around the human body under the $\mathrm{A} 3$ condition is the lowest of the four conditions, which has the least impact on human health.

\section{Acknowledgments}

Project source: Ventilation and air conditioning engineering design and technical services

Project No: HX-2021-004

\section{References:}

1. Cai Fen.Numerical simulation of the influence of airflow organization on indoor air quality [d] .Wuhan: Huazhong University of Science and Technology, 2005.

2. JIANG Y,CHEN Q Y.Using large eddy simulation to study particle motions in a room[J].Indoor Air,2005, 15(1):281-290 .

3. Tu Dayan. Fluid mechanics and fluid machinery [m]. Beijing: China Construction Industry Press, 1988: 107-109.

4. $\mathrm{Hu}$ Kun. ANSYS Fluent example explained [M]. Beijing: Machinery Industry Press, 2018: 13-16.

5. Zhu Mei. Research on indoor environment control method based on pm2.5 concentration standard [d]. Hubei: Wuhan University of Science and Technology, 2014. 